\title{
Surgical mediastinal lymph node staging for non-small-cell lung carcinoma
}

\author{
Pieter W. J. Lozekoot ${ }^{1 \#}$, Jean H. T. Daemen ${ }^{1,2 \#}{ }^{\text {, }}$, Robert R. van den Broek ${ }^{1}$, Jos G. Maessen ${ }^{3,4}$, \\ Michiel H. M. Gronenschild ${ }^{5}$, Yvonne L. J. Vissers ${ }^{1}$, Karel W. E. Hulsewé ${ }^{1}$, Erik R. de Loos ${ }^{1}$ \\ ${ }^{1}$ Division of General Thoracic Surgery, Department of Surgery, Zuyderland Medical Center, Heerlen, The Netherlands; ${ }^{2}$ Faculty of Health, \\ Medicine and Life Sciences (FHML), School for Oncology and Developmental Biology (GROW), Maastricht, The Netherlands; ${ }^{3}$ Department \\ of Cardiothoracic Surgery, Maastricht University Medical Center, Maastricht, The Netherlands; ${ }^{4}$ Faculty of Health, Medicine and Life Sciences \\ (FHML), Cardiovascular Research Institute Maastricht (CARIM), Maastricht, The Netherlands; ${ }^{5}$ Department of Pulmonology, Zuyderland Medical \\ Center, Heerlen, The Netherlands \\ Contributions: (I) Conception and design: All authors; (II) Administrative support: JG Maessen, MHM Gronenschild, KWE Hulsewé; (III) Provision \\ of study materials or patients: PWJ Lozekoot, JHT Daemen, RR van den Broek, YLJ Vissers, ER de Loos; (IV) Collection and assembly of data: \\ PWJ Lozekoot, JHT Daemen, RR van den Broek, YLJ Vissers, ER de Loos; (V) Data analysis and interpretation: PWJ Lozekoot, JHT Daemen, RR \\ van den Broek, YLJ Vissers, ER de Loos; (VI) Manuscript writing: All authors; (VII) Final approval of manuscript: All authors. \\ \#These authors contributed equally to this work. \\ Correspondence to: Erik R. de Loos, MD. Division of General Thoracic Surgery, Department of Surgery, Zuyderland Medical Center, Henri \\ Dunantstraat 5, 6419PC, Heerlen, The Netherlands. Email: e.deloos@zuyderland.nl.
}

Background: The current preferred approach for surgical mediastinal staging of non-small-cell lung carcinoma is video-assisted mediastinoscopy. An alternative technique in which lymph nodes are resected instead of biopsied is video-assisted mediastinoscopic lymphadenectomy (VAMLA) that is suggested to be superior in detecting N2 disease. Yet, evidence is conflicting and furthermore limited by sample size. The objective was to compare mediastinal staging through VAMLA and video-assisted mediastinoscopy.

Methods: A single-center cohort study was conducted. All consecutive patients that underwent surgical mediastinal staging of non-small-cell lung carcinoma by VAMLA (2011 to 2018) were compared to historic video-assisted mediastinoscopy controls (2007 to 2011). Patients with negative surgical mediastinal staging underwent subsequent anatomical resection with systematic regional lymphadenectomy. Primary outcome was the sensitivity and negative predictive value for detecting N2 disease.

Results: Two-hundred-sixty-nine video-assisted mediastinoscopic lymphadenectomies and 118 videoassisted mediastinoscopies were performed. The prevalence of N2 disease was $20 \%$ and $26 \%$ respectively in the VAMLA and video-assisted mediastinoscopy group, while the rate of unforeseen pN2 resulting from lymph node dissection during anatomical resection was $4 \%$ and $11 \%$, respectively. Invasive staging using VAMLA demonstrated superior sensitivity of 0.82 and a negative predictive value of 0.96 when compared to video-assisted mediastinoscopy (0.62 and 0.89, respectively), offering a $64 \%$ decrease in risk of unforeseen $\mathrm{pN} 2$ following anatomical resection. However, VAMLA is also associated with a $75 \%$ risk increase on complications $(\mathrm{P}=0.36)$.

Conclusions: We conclude that performing invasive mediastinal lymph node assessment for staging of non-small-cell lung carcinoma, VAMLA should be the preferred technique with superior sensitivity and negative predictive value in detecting N2 disease. Though, VAMLA is also associated with an increased risk of complications.

\footnotetext{
^ ORCID: 0000-0002-4878-3951.
} 
Keywords: Non-small cell lung carcinoma (NSCLC); video-assisted mediastinoscopic lymphadenectomy (VAMLA); video-assisted mediastinoscopy; sensitivity; unforeseen pN2 disease

Submitted May 01, 2021. Accepted for publication Jun 30, 2021.

doi: $10.21037 /$ tlcr-21-364

View this article at: https://dx.doi.org/10.21037/tlcr-21-364

\section{Introduction}

According to current American and European guidelines $(1,2)$, mediastinal lymph node assessment plays a pivotal role in staging of non-small cell lung carcinoma (NSCLC). Patients suspected of NSCLC routinely undergo an ${ }^{18} \mathrm{~F}$-deoxyglucose positron emission tomography-computed tomography (FDG-PET-CT) scan. When imaging shows suspicious (i.e., enlarged or FDG-avid) ipsilateral or contralateral hilar or mediastinal lymph nodes, in absence of distant organ metastasis, mediastinal staging by endosonography [endo-bronchial (EBUS) and/or endoesophageal ultrasonography (EUS)] is indicated as first best test $(1,2)$. Though, if $\mathrm{N} 2$ disease is suspected on imaging and mediastinal lymph node sampling via $\mathrm{E}(\mathrm{B}) \mathrm{US}$ is negative, surgical mediastinal staging is advised by both the European and American guidelines $(1,2)$. The standard approach for this diagnostic step is video-assisted mediastinoscopy (VAM), as advised by the European guidelines (1). In contrast, American guidelines do not advise on the preferred technique for surgical staging (2). The sensitivity of VAM ranges from 0.75 to 0.95 and NPV from 0.59 to 0.96 $(3-7)$. An alternative technique for surgical mediastinal staging is video-assisted mediastinoscopic lymphadenectomy (VAMLA). In VAMLA, the mediastinal lymph node stations are resected compared to simple biopsy during VAM. Recent studies suggest a superior sensitivity and NPV up to 1.0. However, these series are limited by small sample sizes thereby impairing evidential value (8-10). In addition, the few studies comparing VAM and VAMLA show conflicting evidence regarding sensitivity and NPV $(11,12)$.

The aim of this study is to compare mediastinal staging through VAMLA and VAM, focusing on their sensitivity and NPV in detecting N2 disease among patients suspected for NSCLC. We present the largest VAMLA cohort to date, evaluating its performance for the mediastinal evaluation of NSCLC compared to VAM. This report was written in compliance with the STARD (13) reporting checklist (available at https://dx.doi.org/10.21037/tlcr-21-364).

\section{Methods}

\section{Study design}

A single-center cohort study using prospectively collected, retrospectively reviewed data was conducted at Zuyderland Medical Center (Heerlen, the Netherlands). The study was approved by the local ethics and clinical research committee (METCZ; ID: METCZ20180090, approval date: August $15^{\text {th }}, 2018$ ) of Zuyderland Medical Center (Heerlen, the Netherlands). The study was conducted in accordance with the Declaration of Helsinki (as revised in 2013).

\section{Patients}

All consecutive patients with histologically proven NSCLC who underwent surgical mediastinal staging through VAMLA or VAM between January 2007 (initiation of prospective data collection) and December 2018 at Zuyderland Medical Center (Heerlen, the Netherlands) were eligible for inclusion. Between May 2011 and December 2018 patients underwent VAMLA and were compared to historic VAM controls staged between January 2007 and April 2011. Those with prior mediastinal surgery, prior lung cancer, neoadjuvant therapy or oligometastasis were excluded.

\section{Work-up and surgical techniques}

All patients underwent similar pre-operative workup encompassing an FDG-PET-CT followed by EUS and/ or EBUS in the presence of suspicious ipsilateral or contralateral hilar or mediastinal lymph nodes on imaging. The choice for either technique was based on the stations with suspected involvement. VAM(LA) was performed upon negative $\mathrm{E}(\mathrm{B}) \mathrm{US}$. In addition, $\operatorname{VAM}(\mathrm{LA})$ was indicated in the presence of a non-FDG-avid tumor, central tumor location (defined as: middle one-third of the thorax) and tumor size larger than 3 centimeters, in accordance to European guidelines (1). 
Table 1 Definitions of postoperative adverse events

\begin{tabular}{ll}
\hline Adverse event & Definition \\
\hline $\begin{array}{l}\text { Temporary recurrent } \\
\text { laryngeal nerve palsy }\end{array}$ & $\begin{array}{l}\text { Postoperative dysphagia and/or dysphonia with laryngoscopically confirmed standstill of one or both vocal cords, } \\
\text { recovered within 1 year after VAM(LA) }\end{array}$ \\
$\begin{array}{ll}\text { Permanent recurrent } \\
\text { laryngeal nerve palsy }\end{array}$ & $\begin{array}{l}\text { Persistent postoperative dysphagia and/or dysphonia with laryngoscopically confirmed standstill of one or both } \\
\text { vocal cords that is still present after 1 year after VAM(LA) }\end{array}$ \\
Mediastinitis & $\begin{array}{l}\text { Radiographically confirmed and symptomatic mediastinitis requiring antibiotic treatment within } 30 \text { days after } \\
\text { surgery }\end{array}$ \\
Pneumonia & $\begin{array}{l}\text { The presence of a (new) radiographic infiltrate combined with a decline in oxygenation, fever, purulent sputum, and } \\
\text { leukocytosis within } 30 \text { days following surgery (11) }\end{array}$ \\
Superficial surgical & $\begin{array}{l}\text { The presence of purulent surgical wound drainage, a positive culture and/or requiring surgical drainage or } \\
\text { wound infection }\end{array}$ \\
\hline
\end{tabular}

VAM, video-assisted mediastinoscopy; VAMLA, video-assisted mediastinoscopic lymphadenectomy.

VAM was performed using a standard mediastinoscope with integrated optics connected to a video system. Lymph node stations $2 \mathrm{R}-\mathrm{L}, 4 \mathrm{R}-\mathrm{L}$ and 7 were biopsied. VAMLA was performed according to the technique comprehensively described by Hürtgen et al. (3), using a twin-bladed speculum with integrated optics providing enhanced exposure and facilitating bimanual resection (Video 1). During VAMLA, the same nodal stations were completely resected that were sampled with VAM.

In the absence of $\mathrm{N} 2$ disease after $\operatorname{VAM}(\mathrm{LA})$, anatomical resection was performed within one week. During anatomical resection, intraoperative completing systematic nodal resection was performed in adherence to European guidelines (i.e., adjuvant resection of stations 8 and 9 for the right lower lobe, stations 5 and 6 for the left upper lobe and stations 8 and 9 for the left lower lobe) (14). Station 2, 4 and 7 were solely re-evaluated during anatomical resection in the VAM-group, given that they were already resected in toto by VAMLA. Nevertheless, if adenectomy was not possible during initial VAMLA due to for example dense adhesions, they were re-evaluated during anatomical resection.

All tissue samples were processed and evaluated by a pathologist using similar protocols encompassing hematoxylineosin staining without additional immunohistochemical analysis. In order to maintain uniformity, all TNM stages were classified according to the $7^{\text {th }}$ edition (15) and were converted if defined in a previous edition.

\section{Variables and data acquisition}

Prospectively collected patient charts were retrospectively reviewed for (I) clinical characteristics (gender, age, body mass index, comorbidities, indication for mediastinal staging, tumor location, tumor histology and clinical TNM (cTNM) stage]; (II) mediastinal staging characteristics [mean number and location of lymph node stations resected/biopsied, adherence to the European (i.e., at least resection or biopsy of 4R-L and 7) (1) and American guidelines (i.e., level B: at least resection or biopsy of $2 \mathrm{R}-\mathrm{L}$, $4 \mathrm{R}-\mathrm{L}$ and 7) (2) for mediastinal lymph node staging, presence of positive mediastinal nodes, cTNM stage after $\operatorname{VAM}(\mathrm{LA})$, and postoperative adverse events (see Table 1 for definitions) including severity score according to the Clavien-Dindo Classification (CDC) (13)]; (III) characteristics of subsequent anatomical resection [adherence to the European guidelines on systematic lymph node dissection during anatomical resection (as mentioned above), final pathological (pTNM) stage and unforeseen pN2 disease (i.e., false-negative $\operatorname{VAM}(\mathrm{LA})]$. Unforeseen $\mathrm{pN} 2$ disease was defined as $\mathrm{N} 2$ metastasis resulting from lobe-specific intraoperative systematic nodal resection, when nodal stations evaluated by $\operatorname{VAM}(\mathrm{LA})$ demonstrated no N2 metastasis. For example, metastases in station 5, 6, 8 or 9 , found after anatomical resection were also considered as unforeseen $\mathrm{pN} 2$. Although American guidelines recommend systematic lymph node evaluation at the time of anatomical resection, they do not specify stations to be sampled or dissected (14). Consequently, adherence to the American guidelines could not be assessed

\section{Statistical analyses}

Statistical analyses were performed by SPSS statistics (IBM Corp. IBM SPSS Statistics for MacOS, Version 27.0, 


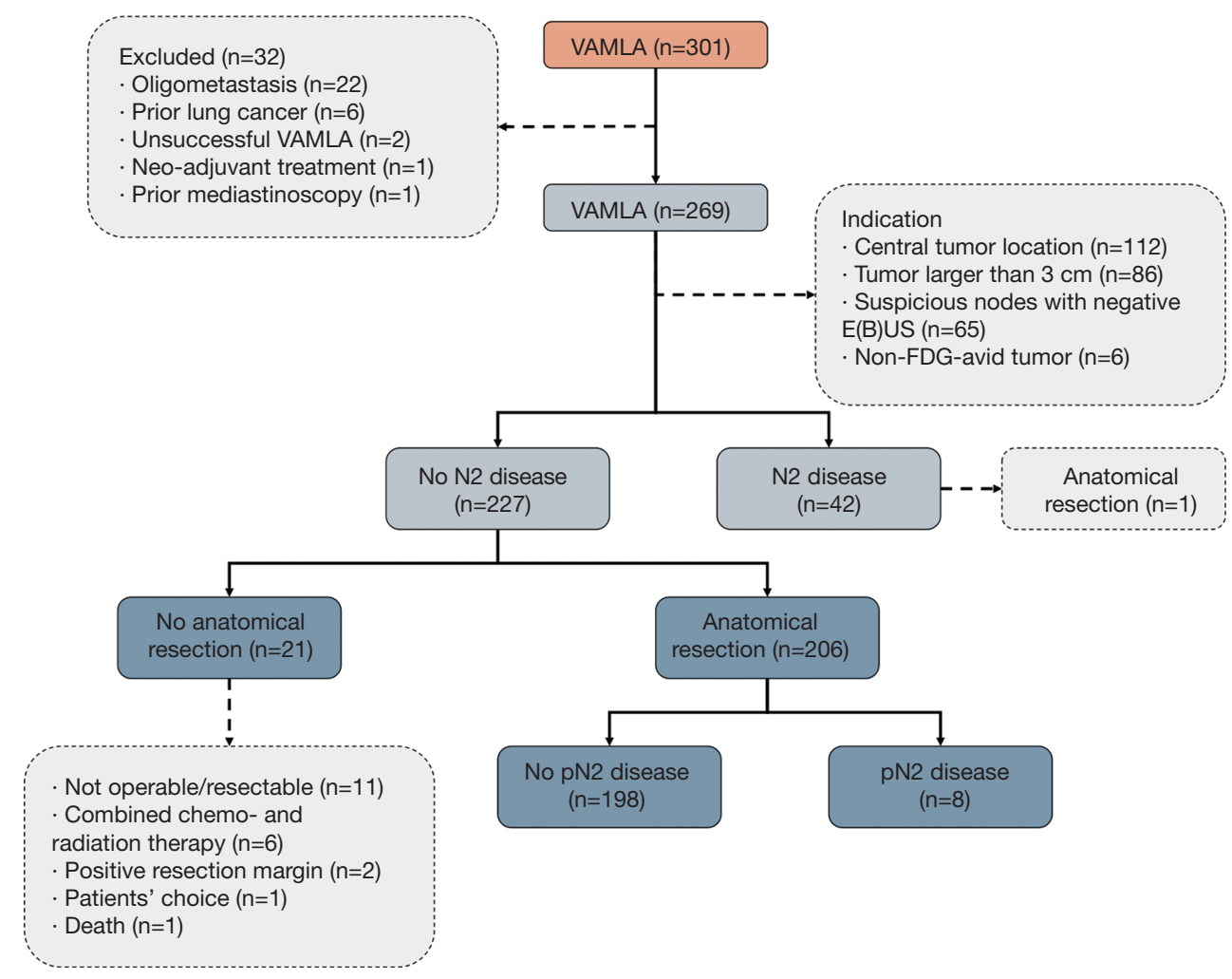

Figure 1 STARD flow chart of patients with histologically proven NSCLC who underwent surgical mediastinal staging through VAMLA and, if applicable, subsequent anatomical resection. NSCLC, non-small-cell lung carcinoma; VAMLA, video-assisted mediastinoscopic lymphadenectomy; EBUS, endo-bronchial ultrasonography; EUS, endo-esophageal ultrasonography; FDG, 18F-deoxyglucose; pN2, pathological N2 disease.

Armonk, NY, USA). Continuous variables were denoted as mean and standard deviation (SD) and assessed for differences by the independent samples $t$-test. Categorical variables were depicted as frequency and percentage and compared using the chi-square-test with post-hoc analyses (by Fisher's exact test) and Bonferroni correction or Fisher's exact test alone. The sensitivity and NPV of VAM(LA) were calculated. These calculations were based on the assumption that the fraction of patients with unforeseen $\mathrm{pN} 2$ disease who underwent an anatomical resection was the same as in patients with negative $\operatorname{VAM}(\mathrm{LA})$ who did not receive an anatomical resection. In addition, patients with positive VAM(LA) did not undergo anatomical resection and were considered to be true positives. Calculating the overall prevalence of $\mathrm{N} 2$ disease [i.e., N2 metastasis found during $\mathrm{VAM}(\mathrm{LA})$ combined with unforeseen $\mathrm{pN} 2$ disease after anatomical resection], patients who had a negative VAM(LA) without subsequent anatomical resection were not considered. Missing data was reported as such. A P value $<0.05$ was considered statistically significant.

\section{Results}

Between January 2007 and December 2018, 436 consecutive patients underwent surgical mediastinal staging, of whom 49 were primarily excluded due to prior mediastinal surgery, prior lung cancer, neoadjuvant treatment and oligometastasis (see the STARD flow charts in Figures 1,2). The remaining 387 patients were divided into a VAMLA $(n=269)$ and VAM $(n=118)$ group. Baseline characteristics are presented in Table 2. Suspicious lymph nodes were significantly $(\mathrm{P}=0.007)$ more often the reason to perform invasive mediastinal staging in the VAM group [38\% $(n=45 / 118)$ ] when compared to the VAMLA group [24\% $(\mathrm{n}=65 / 269)]$. An indication based on tumors larger than 3 centimeters was significantly more frequently observed in the VAMLA group [32\% ( $\mathrm{n}=86 / 269)$; versus VAM: $19 \%$ $(\mathrm{n}=22 / 118) ; \mathrm{P}=0.007]$. Adenocarcinoma was significantly 


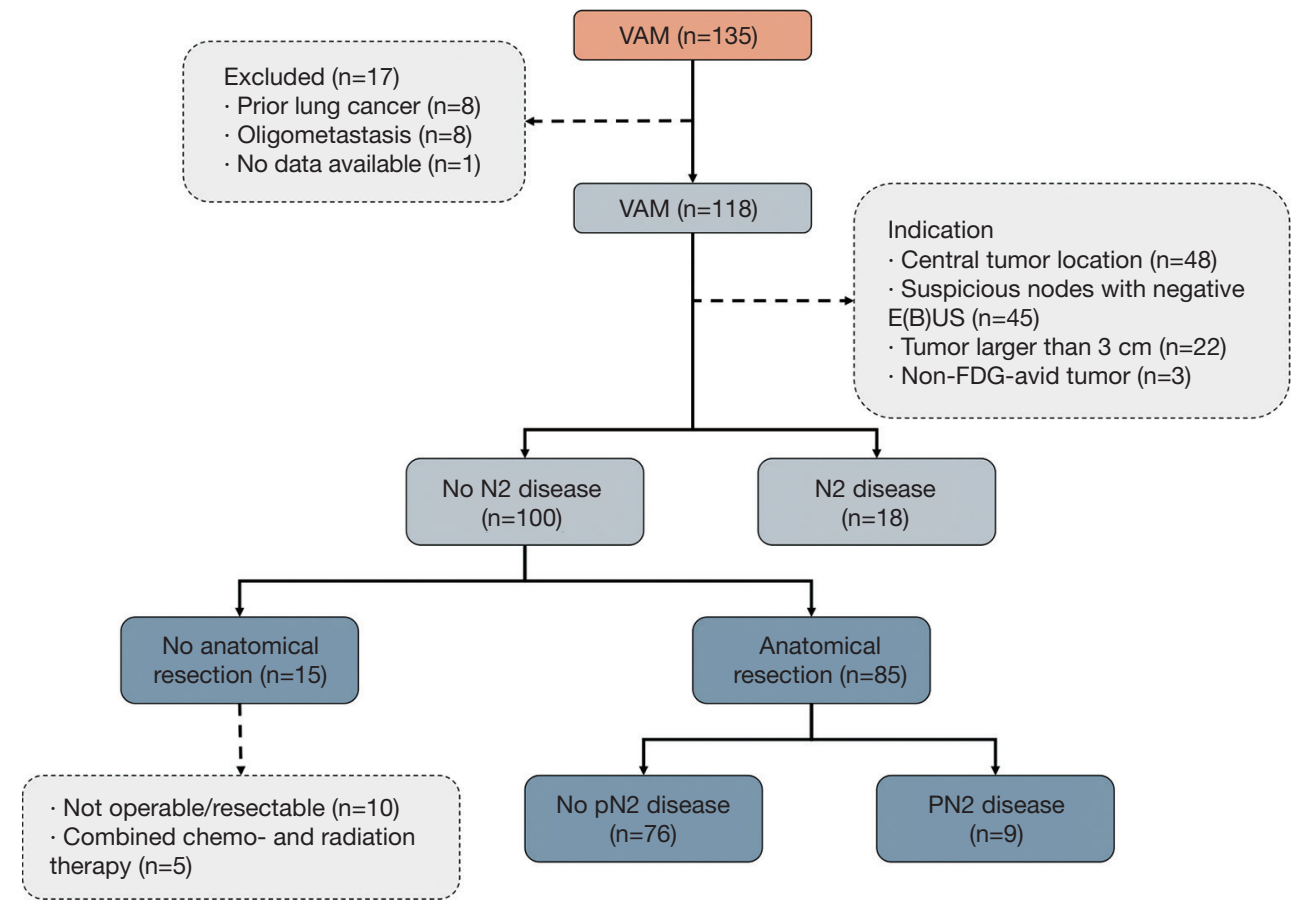

Figure 2 STARD flow chart of patients with histologically proven NSCLC who underwent surgical mediastinal staging through VAM and, if applicable, subsequent anatomical resection. NSCLC, non-small-cell lung carcinoma; VAM, video-assisted mediastinoscopy; EBUS, endobronchial ultrasonography; EUS, endo-esophageal ultrasonography; FDG, 18F-deoxyglucose; pN2, pathological N2 disease.

more common in the VAMLA group $(\mathrm{P}=0.004)$ and large cell carcinoma in the VAM group $(\mathrm{P}<0.001)$.

More lymph node stations were resected during VAMLA [mean: 4.4 (SD: 0.7)] compared to stations biopsied during VAM [mean: 3.5 (SD: 1.0)]. This difference was mainly due to the fact that stations $2 \mathrm{R}-\mathrm{L}$, and $4 \mathrm{R}-\mathrm{L}$ were significantly more often resected in VAMLA (all $\mathrm{P}<0.001$, Table 3). Compliance with the current European and American mediastinal staging guidelines was superior in VAMLA [91\% $(\mathrm{n}=246 / 269)$ and $53 \%(\mathrm{n}=143 / 269)]$ compared to VAM [71\% $(\mathrm{n}=84 / 118)$ and $18 \%(\mathrm{n}=21 / 118)$; both $\mathrm{P}<0.001]$.

The risk of adverse events demonstrated an increase of $75 \%$ for VAMLA (n=19/269), compared to VAM ( $\mathrm{n}=5 / 118$; $\mathrm{P}=0.36)$. Events encompassed temporary recurrent laryngeal nerve palsy (VAMLA $=10, \mathrm{VAM}=4$; CDC- $\mathrm{III}_{a}$; i.e., neuropraxia), permanent recurrent laryngeal nerve palsy $\left(\right.$ VAMLA $=3$; CDC- $\left.\mathrm{III}_{\mathrm{a}}\right)$, mediastinitis $(\mathrm{VAMLA}=3$; CDC-II), pneumonia (VAMLA $=3$; CDC-II) and superficial surgical site infection (VAM $=1$; CDC-I).

Since the overall prevalence of N2 metastasis (i.e., N2 disease found during VAM(LA) combined with unforeseen pN2 disease after anatomical resection) was $20 \%(\mathrm{n}=50 / 248)$ in the VAMLA and 26\% in the VAM ( $\mathrm{n}=27 / 103)$ group, results should be interpreted in the light of a relative risk of 1.31 on N2 disease in the VAM group.

A positive $\operatorname{VAM}(\mathrm{LA})$ was most often observed among patients who underwent mediastinal staging due to suspected nodes on imaging with negative E(B)US [VAMLA: 38\% $(n=18 / 65)$, VAM: 29\% ( $n=13 / 45)]$. Among patients with an indication for mediastinal staging based on a central tumor and tumor size larger than $3 \mathrm{~cm}$, the frequency of a positive VAM(LA) respectively ranged from $6 \%$ to $11 \%$ and $5 \%$ to $14 \%$ (Table 3). A non-FDG-avid tumor as indication for mediastinal staging was not encountered frequently enough ( $\mathrm{n}=9$ total) to allow interpretation.

Of the 227 negative VAMLA cases (i.e., no N2 metastasis found during mediastinal staging), 206 underwent subsequent anatomical resection (Table 4). In this group unforeseen $\mathrm{pN} 2$ disease (i.e., false negative VAMLA) was found in $4 \%(n=8 / 206)$ of cases. Inoperability due to evolving medical conditions or unresectability were the most frequent reasons for withholding surgical resections in patients without N2 metastasis (Figure 1). One patient with a positive VAMLA (based on micrometastasis in nodal station 7) 
Table 2 Clinical patient characteristics

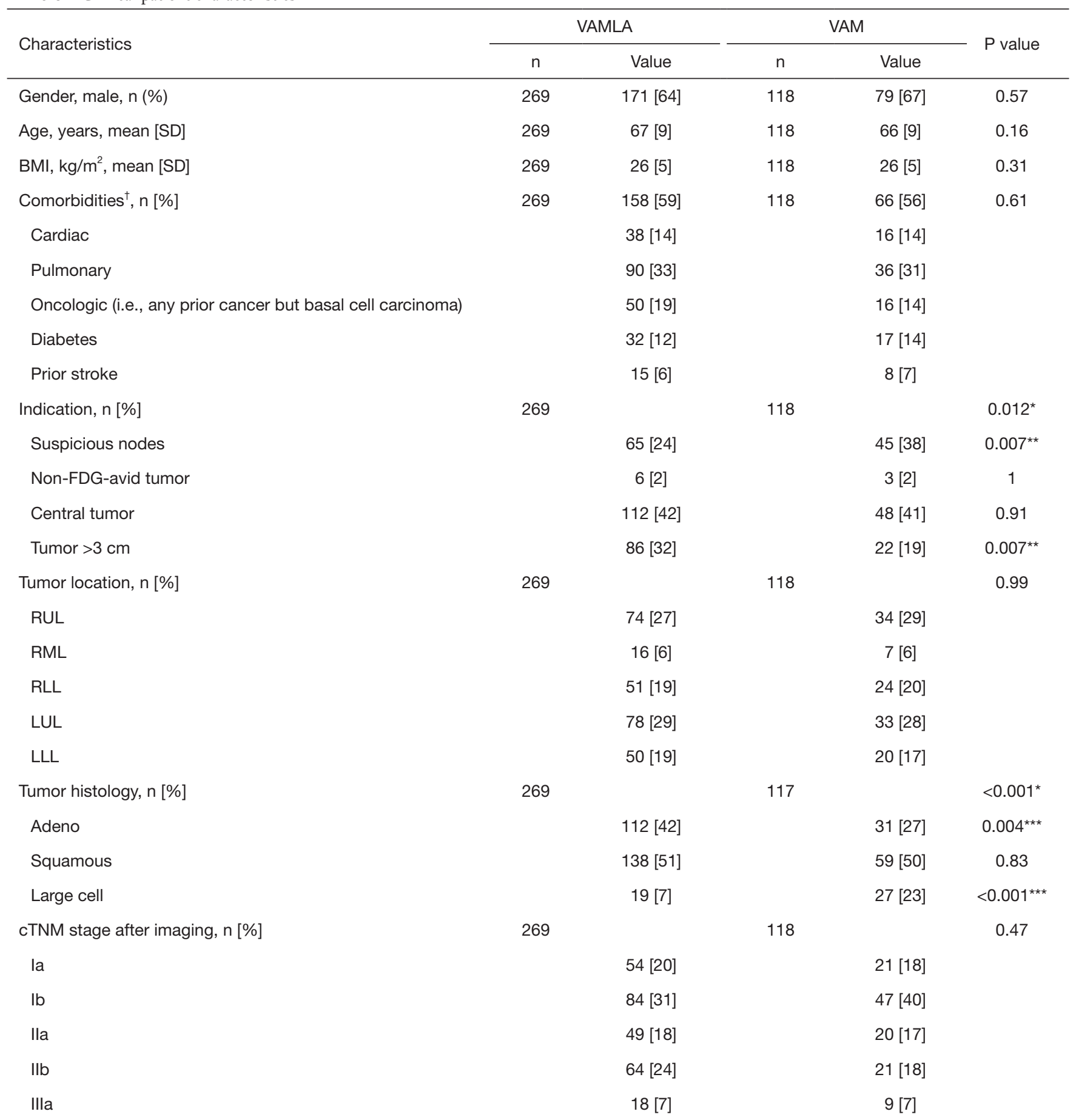

${ }^{*}$, statistically significant at $\mathrm{P}<0.05$. ${ }^{* *}$, statistically significant at $\mathrm{P}<0.013$ after Bonferroni correction. ${ }^{* *}$, statistically significant at $\mathrm{P}<0.017$ after Bonferroni correction. ${ }^{\dagger}$, a single patient can have multiple comorbidities. VAMLA, video-assisted mediastinoscopic lymphadenectomy; VAM, video-assisted mediastinoscopy; SD, standard deviation; BMI, body mass index; FDG, 18F-deoxyglucose; RML, right middle lobe; RLL, right lower lobe; LUL, left upper lobe; LLL, left lower lobe; cTNM, clinical TNM. 
Table 3 Characteristics of mediastinal staging

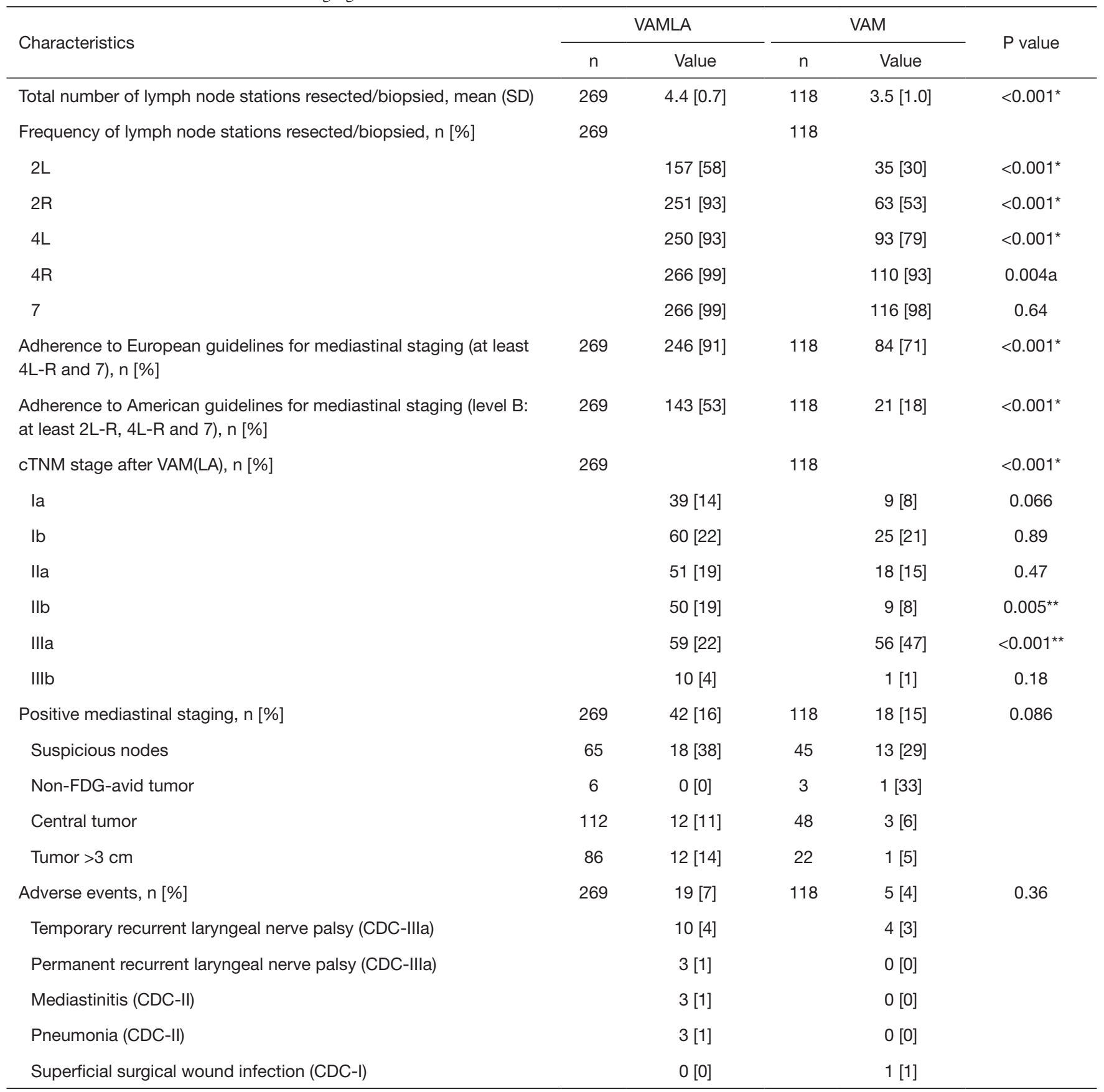

${ }^{*}$, statistically significant at $\mathrm{P}<0.05$. ${ }^{*}$, statistically significant at $\mathrm{P}<0.008$ after Bonferroni correction. VAMLA, video-assisted mediastinoscopic lymphadenectomy; VAM, video-assisted mediastinoscopy; SD, standard deviation; CDC, Clavien-Dindo.

underwent resection but was excluded from sensitivity and NPV analyses. Of the 100 negative VAM cases, fifteen patients had no subsequent surgical intervention due to similar reasons in the VAMLA group (inoperability or irresectability). Unforeseen $\mathrm{pN} 2$ disease in the VAM group after anatomical resection was observed in $11 \%(\mathrm{n}=9 / 85)$ of patients (Figure 2). The prevalence of unforeseen $\mathrm{pN} 2$ disease did significantly differ in favor of VAMLA, when 
Table 4 Characteristics of anatomical resections after negative VAM[LA]

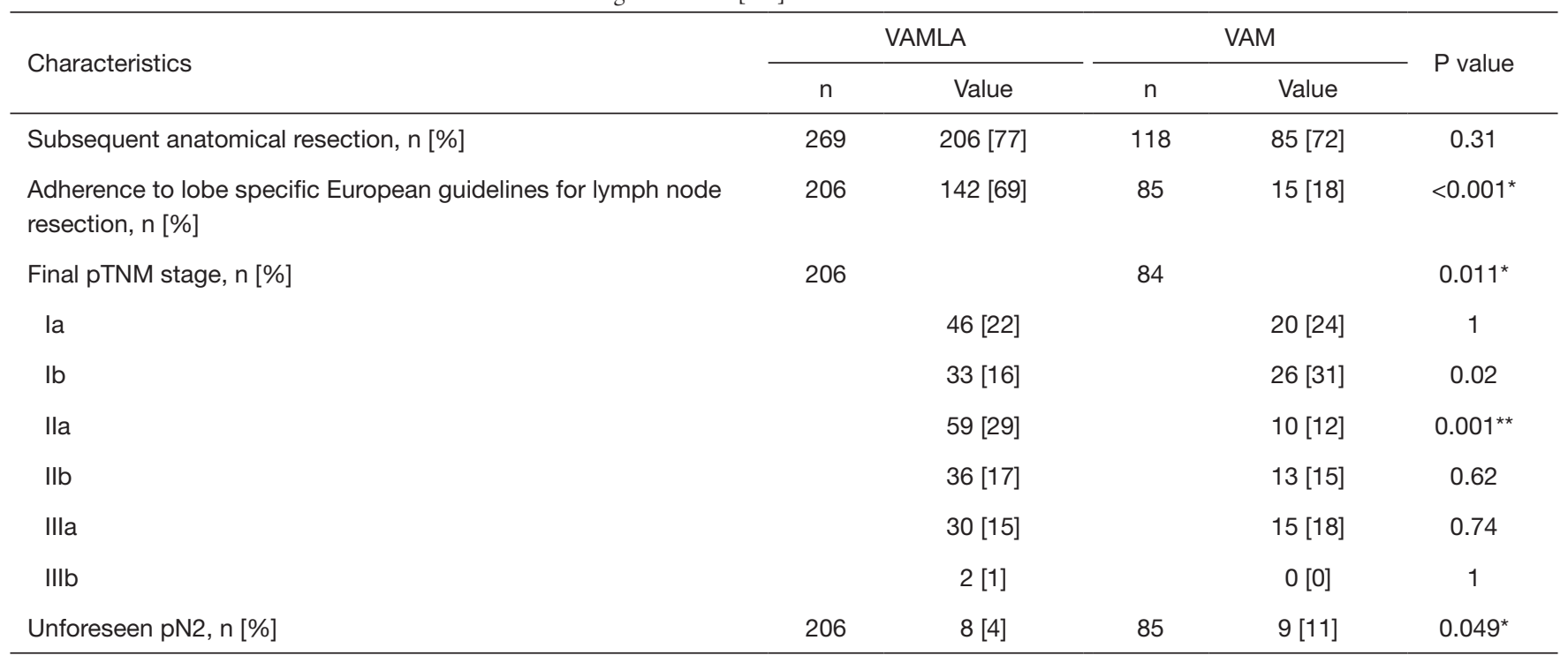

${ }^{*}$, statistically significant at $\mathrm{P}<0.05$. ${ }^{*}$, statistically significant at $\mathrm{P}<0.008$ after Bonferroni correction. VAMLA, video-assisted mediastinoscopic lymphadenectomy; VAM, video-assisted mediastinoscopy; SD, standard deviation; pTNM, pathological TNM; pN2, pathological N2 disease.

being compared to VAM ( $\mathrm{P}=0.049)$.

The sensitivity of VAMLA for detecting $\mathrm{N} 2$ disease was 0.82 ( $\mathrm{n}=42 / 51 ; 95 \%$ CI: 0.69 to 0.92 ) with a NPV of 0.96 (95\% CI: 0.93 to 0.98 ). Corresponding values for VAM were $0.62(\mathrm{n}=18 / 29 ; 95 \%$ CI: 0.42 to 0.79$)$ and $0.89(95 \%$ CI: 0.84 to 0.93$)$.

Clinical characteristics of patients with unforeseen pN2 disease are depicted in Table 5. Missed mediastinal metastases were single station in all but one patient. In 5 out of 9 VAM patients this concerned lymph node stations that were accessible by VAM. In the remaining four VAM patients, metastases were found in station 5 , which cannot be reached via standard VAM(LA). In 2 of the 8 false negative cases in the VAMLA group metastasis were found in nodal stations that should have been resected. This included one patient in whom N7 was only partially resected due to extensive peri-nodal tissue induration.

The lobe specific European guidelines for lymph node resection during anatomical resection were adhered to in $69 \%(n=142 / 206)$ and $18 \%(n=15 / 85)$ of patients in the VAMLA and VAM group, respectively.

\section{Discussion}

The objective of this single-center cohort study was to compare surgical mediastinal staging for NSCLC through
VAMLA and VAM, focusing on their ability to detect N2 disease.

Based on our data we found superior sensitivity and NPV for VAMLA (0.82 and 0.96, respectively) for detecting N2 disease, compared with VAM (0.62 and 0.89, respectively). The rate of unforeseen $\mathrm{pN} 2$ was $4 \%(\mathrm{n}=8 / 206)$ for VAMLA and $11 \%(\mathrm{n}=9 / 85)$ for VAM. VAMLA thus offers a significantly better staging that results in a $64 \%$ risk reduction in unforeseen pN2. However, VAMLA is also associated with an increased complication rate of $75 \%(\mathrm{n}=19 / 269)$ compared to VAM $(\mathrm{n}=5 / 118 ; \mathrm{P}=0.36)$, predominantly due to a $66 \%$ [VAMLA: $5 \%$ (13/269); VAM: $3 \%(3 / 118)]$ increase in the risk of recurrent laryngeal nerve palsies. Though, the majority of these concerned neuropraxia and thus were of temporary nature. Whether this increased complication rate justifies the risk reduction in unforeseen $\mathrm{pN} 2$ may be questioned. It could potentially be justified for patients with a high prior probability of N2 disease in combination, such as patients with suspected mediastinal lymph nodes and negative E(B)US. Though, the morbidity associated with $\operatorname{VAM}(\mathrm{LA})$ has made it an unattractive option for North American surgeons who favor the sole use of $\mathrm{E}(\mathrm{B}) \mathrm{US}$ which is associated with negligible morbidity (15).

The NPV in the VAM group falls within the range of previously reported series (0.59 to 0.96$)$ (16-20). Similar 
Table 5 Characteristics of individual patients with unforeseen $\mathrm{pN} 2$ following anatomical resection

\begin{tabular}{|c|c|c|c|c|c|c|c|c|c|c|}
\hline $\begin{array}{l}\text { Surgical } \\
\text { modality }\end{array}$ & $\begin{array}{l}\text { Tumor } \\
\text { location }\end{array}$ & $\begin{array}{l}\text { Indication for } \\
\text { VAM(LA) }\end{array}$ & $\begin{array}{l}\text { cTNM stage } \\
\text { after imaging }\end{array}$ & $\begin{array}{l}\text { Tumor } \\
\text { histology }\end{array}$ & $2 \mathrm{~L}$ & $2 \mathrm{R}$ & $4 \mathrm{~L}$ & $4 \mathrm{R}$ & 7 & $\begin{array}{l}\text { Positive } \\
\text { node(s) }\end{array}$ \\
\hline \multirow[t]{5}{*}{ VAMLA } & LLL & Central tumor & $\mathrm{lb}$ & Adeno & Yes & Yes & Yes & Yes & Yes & 6 and 7 \\
\hline & LUL & Central tumor & Ilb & Adeno & Yes & Yes & Yes & Yes & Yes & 5 \\
\hline & LUL & Central tumor & la & Squamous & No & Yes & Yes & Yes & Yes & 6 \\
\hline & LUL & Central tumor & Ilb & Squamous & Yes & Yes & Yes & Yes & Yes & 9 \\
\hline & RLL & Tumor $>3 \mathrm{~cm}$ & Ila & Squamous & No & Yes & Yes & Yes & Yes & 7 \\
\hline \multirow{6}{*}{ VAM } & RLL & Central tumor & $\mathrm{lb}$ & Squamous & No & Yes & Yes & Yes & Yes & 7 \\
\hline & RLL & Suspicious nodes & $\mathrm{lb}$ & Squamous & No & No & Yes & Yes & Yes & 7 \\
\hline & LUL & Suspicious nodes & Ilb & Squamous & Yes & Yes & Yes & Yes & Yes & 5 \\
\hline & LUL & Tumor $>3 \mathrm{~cm}$ & $\mathrm{Ilb}$ & Large cell & No & Yes & Yes & Yes & Yes & 5 \\
\hline & LUL & Central tumor & Ila & Large cell & No & No & Yes & Yes & Yes & 5 \\
\hline & LLL & Suspicious nodes & Illb & Large cell & No & No & Yes & Yes & Yes & 7 \\
\hline
\end{tabular}

VAM, video-assisted mediastinoscopy; VAMLA, video-assisted mediastinoscopic lymphadenectomy; cTNM, clinical TNM; LUL, left upper lobe; LLL, left lower lobe; RUL, right upper lobe; RML, right middle lobe; RLL, right lower lobe.

observations are made for VAMLA with reported NPVs ranging from 0.84 up to $1.0(3,4,6,7,21,22)$. These variations demonstrate considerable heterogeneity among studies, that might possibly be explained by differences in sample size, inclusion criteria, work-up and use of additional diagnostics (e.g., extended mediastinoscopy or mediastinotomy). The NPV reported in the current series should thus be interpreted within the context that all patients suspected for NSCLC underwent E(B)US in the presence of reachable suspicious lymph nodes on FDG-PET-CT. In addition, $\operatorname{VAM}(\mathrm{LA})$ was indicated after negative $\mathrm{E}(\mathrm{B}) \mathrm{US}$, or in the presence of a non-FDG-avid tumor, central tumor location and tumor size larger than 3 centimeters.

Suspicious lymph nodes were more often the reason to perform invasive mediastinal staging in the VAM group, while a tumor larger than 3 centimeters was more frequently observed as an indication in the VAMLA group. The indication for mediastinal staging in tumors larger than $3 \mathrm{~cm}$ was not applied compellingly during the early enrollment period (i.e., at the time when surgical mediastinal staging was performed through VAM) as this recommendation had not been embodied in the national Dutch guidelines at that time. Gradually, adherence to European guidelines (that included the indication in tumors $>3 \mathrm{~cm}$ ) intensified and a shift was made to VAMLA, potentially explaining its increased frequency.

Regarding the differences in tumor histology: adenocarcinoma was more often observed in the VAMLA and large cell carcinoma in the VAM group. However, both definitions have an overlap and their institutional use shifted during the enrollment period.

In the VAMLA and VAM group, respectively $5 \%$ and $10 \%$ of patients without $\mathrm{N} 2$ disease found after surgical mediastinal staging did not undergo subsequent anatomical lung resection. This resulted from the primary objective for mediastinal staging being assessment of nodal status to determine chemoradiation treatment strategy in these selected patients who were already deemed inoperable/ 
unresectable.

As reported earlier (6), we demonstrated that VAMLA led to an increase in the number of stations evaluated and thus improved adherence to current guidelines for mediastinal staging $(1,2)$. This may be due to the use of a twin-bladed scope enabling bimanual dissection and enlarging the field of dissection, thereby improving visibility and identification of lymph nodes. Alternatively, these increased number of stations evaluated may be biased due to the use of historical controls which do not account for enhanced awareness and, as mentioned previously, improved guideline adherence over time. Though, the latter may be challenged given that the adherence to anatomical resection guidelines was also superior for the VAMLA group (69\%; compared to $18 \%$ for VAM) and was, moreover, considerably higher compared to a nationwide study in the Netherlands by van der Woude et al. (23). During the same enrollment period as our VAMLA group, van der Woude et al., revealed a complete N2 lymph node dissection rate (defined as: at least three mediastinal lymph node stations including station 7) of approximately $27 \%$ for anatomical resections through a minimally invasive approach among patients with cN01 disease staged by E(B)US and/or mediastinoscopy (23). Albeit a partial effect of improved adherence over time is, next to the potential superiority of VAMLA, likely to be present since we also intensified our adherence to European guidelines on indications for surgical mediastinal staging as above-mentioned.

Anatomical resection within one week following VAM(LA), as performed in the present study, may be technically more demanding due to the presence of mediastinal tissue reaction and induration. At this point, VAMLA is at advantage since lymph node stations 2, 4 and 7 are already being resected in toto during mediastinal staging, because of which the touched stations do not require re-evaluation upon anatomical resection. In addition, the stations which still require resection during anatomical resection (i.e., station 5, 6, 8 and/or 9 depending on tumor location) are in previously untouched areas, not directly complicating their resection. In contrast VAM requires re-evaluation of stations 2, 4 and 7. Evaluating the difference regarding complications after anatomical resection may be of great interest for future research given the preceding differences between anatomical resection after respectively VAM and VAMLA.

The traditional 'Achilles-heel' of both VAM and VAMLA (4) consists of station $2 \mathrm{~L}$ due to its direct anatomical relation with the recurrent laryngeal nerve and aortic arch. In addition, ipsilateral station 2 is known for being difficult to reach when performing lobe-specific lymph node dissection during anatomical resection through conventional videoassisted thoracoscopy (24), potentially leading to a (microscopic) incomplete lymphadenectomy. Though, this potential issue can be circumvented by complete resection of stations 2L-R during VAMLA.

We reported a complication rate of $7 \%(n=19 / 269)$ and $4 \%(n=5 / 118)$ for VAMLA and VAM, respectively. These complication rates are both slightly higher than in previously published VAMLA- $(3,5,21,22)$ and VAMcohorts $(17,20)$. The most observed complication after VAMLA was laryngeal recurrent nerve palsy in $5 \%$ $(n=13 / 269)$ of cases, versus $3 \%(n=4 / 118)$ in VAM cases (temporary and permanent combined). Appropriate visualization of the recurrent nerve, systematic sampling of the left paratracheal nodes instead of en bloc resection and the use of endoclips for hemostasis instead of electrocautery are all measures that can be taken in order to prevent laryngeal recurrent nerve palsies during $\operatorname{VAMLA}(5,21)$.

In addition, we recently published our learning process of VAMLA and demonstrated a considerable drop in complication rates with frequent exposure after an initial 16 to 17 cases, advocating a minimal volume-limit for surgeons (25). In contrast to this positive effect on complications, no relation was found between the occurrence of unforeseen pN2 and learning process of VAMLA. However, it should be noted that this study reported a lower unforeseen $\mathrm{pN} 2$ rate of $3 \%$ that was based on a more heterogeneous patient population (25).

We reported an overall N2 metastasis prevalence of $22 \%(\mathrm{n}=77 / 251)$. This is relatively low in comparison to rates reported in current literature $(21 \%$ to $32 \%)(6,7)$. The diagnostic yield of E(B)US in our center may possibly be higher but is unknown at this time. In addition, the indications for E(B)US may differ among centers, affecting the rate of $\mathrm{N} 2$ disease found during surgical mediastinal staging and subsequent resection. In the current series, $\mathrm{E}(\mathrm{B}) \mathrm{US}$ was only indicated in the presence of suspicious ipsilateral or contralateral hilar or mediastinal lymph nodes on imaging. In cases with a non-FDG-avid tumor, centrally located tumor and a tumor size larger than 3 centimeters without suspicious nodes, invasive mediastinal staging was not preceded by E(B)US. However, experience with $\mathrm{E}(\mathrm{B})$ US is expanding and several centers already perform $\mathrm{E}(\mathrm{B})$ US for all the aforementioned indications to rule out mediastinal disease.

Although the unforeseen pN2 rate after VAMLA of $4 \%$ 
is considered acceptable and is in agreement with the revised European guidelines that aim at a rate below 10\% (1), improvements are possible. As pointed out in Table 5, twelve out of 17 combined VAM(LA) patients with unforeseen $\mathrm{pN} 2$ had left-sided tumors with the main indication for surgical staging being a central tumor location. Transcervical extended mediastinal lymphadenectomy (TEMLA) aimed at station 5 and 6 theoretically could have reduced the false negative rate of VAMLA, as 5 out of 8 patients had single station tumor spread in these para-aortic and subaortic nodes that are not sampled through $\operatorname{VAM}(\mathrm{LA})$. However, given the concern on morbidity and mortality associated with TEMLA (1) leading to $>20 \%$ of patients becoming medically inoperable (26), video-assisted thoracoscopic surgery (VATS) may provide a safer approach to sample station 5 and 6 before committing to anatomical resection (27). Moreover, station 5 and 6 could in theory also be sampled via EUS in expert hands (28). Evaluation of these stations is of great interest for future research to reduce the occurrence of futile surgical interventions. Though, patients with isolated sub-aortic nodal metastases often behave more like N1-disease and might be eligible for primary anatomical resection with improved survival compared to survival following anatomical resection of metastatic disease in other mediastinal lymph node stations (29).

Finally, missed mediastinal metastases were single station in all but one patient, requiring these patients to undergo adjuvant treatment following surgery. It is well known that there is a wide variety in the prognosis of multilevel or single station N2 disease in NSCLC (30), whereas the latter is associated with a significantly better prognosis and are thus often operated. Neo-adjuvant treatment in these patients is not associated with better outcomes in comparison with adjuvant treatment (31) and might thus question the added benefit of surgical mediastinal staging procedures and their associated complication risks. In its turn, complete mediastinal staging might provide a mediastinal nodes ratio, showing potential in patient tailored treatment (32-34), whereas optimal non-invasive endosonography may even omit the need for surgical mediastinal staging. In order to choose optimal therapy, patient counselling may start to play a bigger role in future diagnostic strategies for NSCLC.

\section{Limitations}

We present the largest VAMLA cohort to date with 269 patients and compared its performance to VAM $(n=118)$.
Other comparative studies included a maximum of 89 VAMLA patients $(6,7)$. However, this also directly imposes a concern for the external applicability of our results, considering the relatively large experience of surgeons in VAMLA. The majority of VAMLAs $(n=243 / 269)$ were performed by 6 distinct surgeons, while the majority of VAMs were performed by 4 different surgeons $(n=92 / 118)$. The remaining procedures were performed by residents or surgeons who performed less than 10 procedures each, potentially affecting outcome. Less experienced hands may show higher complication rates; however, this applies for both techniques. Another limitation concerns that the study was not powered to detect the statistical significance of clinically important differences in the rates of uncommon complications. The study was, moreover, limited by the use of historic controls and a relatively lengthy enrollment period of 11 years inducing potential heterogeneity due to the introduction of pathological, radiological and surgical innovations and the fact that emphasis shifted in the workup and treatment of patients with NSCLC. The use of multivariate analysis techniques or matching of participants could have reduced the amount of bias, however, the sample size was deemed inadequately. During the course of this study, we switched from VAM to VAMLA (in 2011) for mediastinal staging and from multiportal to uniportal VATS (in 2015) for anatomical resection. Adoption of both new procedures necessitated a learning process. In addition, although prospectively collected data were used, missing data regarding tumor histology and final pTNM stage were present in one patient. Given the above-mentioned limitations, the current evidence should be corroborated by future, adequately powered, randomized controlled trials.

\section{Future perspectives}

The combination of E(B)US (11) has led to a further refinement in the diagnostic work-up for NSCLC as described in the combined European Society of Gastrointestinal Endoscopy (ESGE)/European Respiratory Society (ERS) and the European Society of Thoracic Surgeons (ESTS) guideline on combined endobronchial and esophageal endosonography (12). A diagnostic workup combining negative dual endosonography followed by surgical mediastinoscopy, led to the detection of mediastinal metastatic disease in $9 \%$ of patients with a sensitivity of 0.94 (35). Although we found a higher mediastinal disease rate after both VAMLA and VAM [16\% $(\mathrm{n}=42 / 269)$ and $15 \%(\mathrm{n}=18 / 118)$, respectively], our reported unforeseen 
pN2 rate was considerably lower in the VAMLA group [4\% $(n=8 / 206)]$ compared to reported rates following negative dual endosonography only (23\%) (35). Following the results of Annema et al. (35), the ongoing MEDIASTrial investigates whether dual endosonography alone is non-inferior to the addition of subsequent surgical mediastinoscopy, thereby potentially reducing morbidity and treatment delay (36). However, we advocate careful subgroup analyses as the rates of $\mathrm{N} 2$ disease are likely to differ among indications for mediastinal staging (e.g., suspicious nodes on pre-operative imaging).

In the present study, the absence of N2-disease after VAM(LA), either minimal or multi-level, selected candidates for subsequent anatomical resection, while its presence indicated non-surgical therapy [i.e., chemo(radiation) therapy] as initial treatment course. Though, in future practice the involved mediastinal nodes ratio might prove to be a better criterium for tailored treatment (32-34). This in turn may result in an increased interest for mediastinal lymphadenectomies. For example, in inoperable patients undergoing mediastinal staging to rule out N2 disease to have non-surgical treatment such as stereotactic body radiation therapy. Moreover, with advancing insight and techniques, space was created for resection after neoadjuvant treatment or anatomical resection followed by adjuvant therapy in the presence of minimal N2 disease.

In the present study, anatomical resection was performed within 1 week in the absence of $\mathrm{N} 2$ disease after $\operatorname{VAM}(\mathrm{LA})$. Theoretically speaking, both procedures could be performed in the same setting. Consequently, the patient only requires a single surgery which may ease surgical planning and enhance overall recovery, but also eliminates the patient's uncertainty while waiting for the VAM(LA) results. However, frozen sections are associated with limited reliability for the analysis of lymph node metastases. An alternative may be to use One Step Nucleic Acid Amplification, a novel molecular-based diagnostic to detect lymph node metastases, which takes around 30 minutes to obtain a final result. Its first results in NSCLC patients are promising $(37,38)$. The concept of performing both procedures in the same setting is promising and should be subject of future research.

\section{Conclusions}

We evaluated the value of surgical mediastinal staging using VAMLA versus VAM in a NSCLC population to detect $\mathrm{N} 2$ disease. Invasive staging using VAMLA should be the preferred technique given its superior sensitivity and NPV when compared to VAM, depicted by a $64 \%$ decrease in the risk of unforeseen $\mathrm{pN} 2$ following anatomical resection in patients undergoing VAMLA. However, VAMLA was also associated with a $75 \%$ increase in the risk of complications including a $66 \%$ increase in the risk of recurrent laryngeal nerve palsies. Though, the majority were of temporary nature. Future studies should aim to corroborate this evidence by adequately powered randomized controlled trials.

\section{Acknowledgments}

The authors would like to gratefully acknowledge James van Bastelaar, MD, PhD (Department of Surgery, Zuyderland Medical Center, Heerlen, the Netherlands) for grammatical review and editing of the manuscript.

Funding: None.

\section{Footnote}

Reporting Checklist: The authors have completed the STARD reporting checklist. Available at https://dx.doi. org/10.21037/tlcr-21-364

Data Sharing Statement: Available at https://dx.doi. org/10.21037/tlcr-21-364

Peer Review File: Available at https://dx.doi.org/10.21037/ tlcr-21-364

Conflicts of Interest: All authors have completed the ICMJE uniform disclosure form (available at https://dx.doi. org/10.21037/tlcr-21-364). The authors have no conflicts of interest to declare.

Ethical Statement: The authors are accountable for all aspects of the work in ensuring that questions related to the accuracy or integrity of any part of the work are appropriately investigated and resolved. The study was approved by the local ethics and clinical research committee (METCZ; ID: METCZ20180090, approval date: August $15^{\text {th }}, 2018$ ) of Zuyderland Medical Center (Heerlen, the Netherlands). The study was conducted in accordance with the Declaration of Helsinki (as revised in 2013).

Open Access Statement: This is an Open Access article distributed in accordance with the Creative Commons 
Attribution-NonCommercial-NoDerivs 4.0 International License (CC BY-NC-ND 4.0), which permits the noncommercial replication and distribution of the article with the strict proviso that no changes or edits are made and the original work is properly cited (including links to both the formal publication through the relevant DOI and the license). See: https://creativecommons.org/licenses/by-nc-nd/4.0/.

\section{References}

1. De Leyn P, Dooms C, Kuzdzal J, et al. Revised ESTS guidelines for preoperative mediastinal lymph node staging for non-small-cell lung cancer. Eur J Cardiothorac Surg 2014;45:787-98.

2. Silvestri GA, Gonzalez AV, Jantz MA, et al. Methods for staging non-small cell lung cancer: Diagnosis and management of lung cancer, 3rd ed: American College of Chest Physicians evidence-based clinical practice guidelines. Chest 2013;143:e211S-e250S.

3. Hürtgen M, Friedel G, Toomes H, et al. Radical videoassisted mediastinoscopic lymphadenectomy (VAMLA)-technique and first results. Eur J Cardiothorac Surg 2002;21:348-51.

4. Leschber G, Holinka G, Linder A. Video-assisted mediastinoscopic lymphadenectomy (VAMLA)--a method for systematic mediastinal lymphnode dissection. Eur J Cardiothorac Surg 2003;24:192-5.

5. Witte B, Wolf M, Huertgen M, et al. Video-assisted mediastinoscopic surgery: clinical feasibility and accuracy of mediastinal lymph node staging. Ann Thorac Surg 2006;82:1821-7.

6. Sayar A, Citak N, Metin M, et al. Comparison of video-assisted mediastinoscopy and video-assisted mediastinoscopic lymphadenectomy for lung cancer. Gen Thorac Cardiovasc Surg 2011;59:793-8.

7. Turna A, Demirkaya A, Ozkul S, et al. Video-assisted mediastinoscopic lymphadenectomy is associated with better survival than mediastinoscopy in patients with resected non-small cell lung cancer. J Thorac Cardiovasc Surg 2013;146:774-80.

8. Bossuyt PM, Reitsma JB, Bruns DE, et al. STARD 2015: an updated list of essential items for reporting diagnostic accuracy studies. BMJ 2015;351:h5527.

9. Lardinois D, De Leyn P, Van Schil P, et al. ESTS guidelines for intraoperative lymph node staging in non-small cell lung cancer. Eur J Cardiothorac Surg 2006;30:787-92.

10. Mirsadraee S, Oswal D, Alizadeh Y, et al. The 7th lung cancer TNM classification and staging system: Review of the changes and implications. World J Radiol 2012;4:128-34.

11. Korevaar DA, Crombag LM, Cohen JF, et al. Added value of combined endobronchial and oesophageal endosonography for mediastinal nodal staging in lung cancer: a systematic review and meta-analysis. Lancet Respir Med 2016;4:960-8.

12. Vilmann P, Clementsen PF, Colella S, et al. Combined endobronchial and esophageal endosonography for the diagnosis and staging of lung cancer: European Society of Gastrointestinal Endoscopy (ESGE) Guideline, in cooperation with the European Respiratory Society (ERS) and the European Society of Thoracic Surgeons (ESTS). Endoscopy 2015;47:545-59.

13. Clavien PA, Barkun J, de Oliveira ML, et al. The ClavienDindo classification of surgical complications: five-year experience. Ann Surg 2009;250:187-96.

14. Howington JA, Blum MG, Chang AC, et al. Treatment of stage I and II non-small cell lung cancer: Diagnosis and management of lung cancer, 3 rd ed: American College of Chest Physicians evidence-based clinical practice guidelines. Chest 2013;143:e278S-e313S.

15. Zhang R, Ying K, Shi L, et al. Combined endobronchial and endoscopic ultrasound-guided fine needle aspiration for mediastinal lymph node staging of lung cancer: a metaanalysis. Eur J Cancer 2013;49:1860-7.

16. Anraku M, Miyata R, Compeau C, et al. Videoassisted mediastinoscopy compared with conventional mediastinoscopy: are we doing better? Ann Thorac Surg 2010;89:1577-81.

17. Cho JH, Kim J, Kim K, et al. A comparative analysis of video-assisted mediastinoscopy and conventional mediastinoscopy. Ann Thorac Surg 2011;92:1007-11.

18. Karfis EA, Roustanis E, Beis J, et al. Video-assisted cervical mediastinoscopy: our seven-year experience. Interact Cardiovasc Thorac Surg 2008;7:1015-8.

19. Rami-Porta R, Call S. Invasive staging of mediastinal lymph nodes: mediastinoscopy and remediastinoscopy. Thorac Surg Clin 2012;22:177-89.

20. Leschber G, Sperling D, Klemm W, et al. Does videomediastinoscopy improve the results of conventional mediastinoscopy? Eur J Cardiothorac Surg 2008;33:289-93.

21. Call S, Obiols C, Rami-Porta R, et al. Video-Assisted Mediastinoscopic Lymphadenectomy for Staging Non-Small Cell Lung Cancer. Ann Thorac Surg 2016;101:1326-33.

22. Yoo DG, Kim YH, Kim DK, et al. Clinical feasibility 
and surgical benefits of video-assisted mediastinoscopic lymphadenectomy in the treatment of resectable lung cancer. Eur J Cardiothorac Surg 2011;40:1483-6.

23. van der Woude L, Wouters MWJM, Hartemink KJ, et al. Completeness of lymph node dissection in patients undergoing minimally invasive- or open surgery for nonsmall cell lung cancer: A nationwide study. Eur J Surg Oncol 2021;47:1784-90.

24. Kim HJ, Kim YH, Choi SH, et al. Video-assisted mediastinoscopic lymphadenectomy combined with minimally invasive pulmonary resection for left-sided lung cancer: feasibility and clinical impacts on surgical outcomes†. Eur J Cardiothorac Surg 2016;49:308-13.

25. Daemen JHT, van den Broek RAM, Lozekoot PWJ, et al. The learning curve of video-assisted mediastinoscopic lymphadenectomy for staging of non-small-cell lung carcinoma. Interact Cardiovasc Thorac Surg 2020;31:527-35.

26. Kużdżał J, Warmus J, Grochowski Z. Optimal mediastinal staging in non-small cell lung cancer: what is the role of TEMLA and VAMLA? Lung Cancer 2014;86:1-4.

27. Cerfolio RJ, Bryant AS, Eloubeidi MA. Accessing the aortopulmonary window (\#5) and the paraaortic (\#6) lymph nodes in patients with non-small cell lung cancer. Ann Thorac Surg 2007;84:940-5.

28. Bendzsak A, Oliveira R, Goudie E, et al. Evaluation of the Mediastinum: Differentiating Between Stations 4L, 5, and 6 Using EBUS and EUS. Ann Thorac Surg 2017; 103:e219-21.

29. Patterson GA, Piazza D, Pearson FG, et al. Significance of metastatic disease in subaortic lymph nodes. Ann Thorac Surg 1987;43:155-9.

30. Andre F, Grunenwald D, Pignon JP, et al. Survival of patients with resected N2 non-small-cell lung cancer: evidence for a subclassification and implications. J Clin Oncol 2000;18:2981-9.

Cite this article as: Lozekoot PWJ, Daemen JHT, van den Broek RR, Maessen JG, Gronenschild MHM, Vissers YLJ, Hulsewé KWE, de Loos ER. Surgical mediastinal lymph node staging for non-small-cell lung carcinoma. Transl Lung Cancer Res 2021;10(8):3645-3658. doi: 10.21037/tlcr-21-364
31. Tao X, Yuan C, Zheng D, et al. Outcomes comparison between neoadjuvant chemotherapy and adjuvant chemotherapy in stage IIIA non-small cell lung cancer patients. J Thorac Dis 2019;11:1443-55.

32. Chen W, Zhang C, Wang G, et al. Feasibility of nodal classification for non-small cell lung cancer by merging current $\mathrm{N}$ categories with the number of involved lymph node stations. Thorac Cancer 2019;10:1533-43.

33. Lee GD, Kim DK, Moon DH, et al. A comparison of the proposed classifications for the revision of $\mathrm{N}$ descriptors for non-small-cell lung cancer. Eur J Cardiothorac Surg 2016;49:580-8.

34. Wisnivesky JP, Arciniega J, Mhango G, et al. Lymph node ratio as a prognostic factor in elderly patients with pathological N1 non-small cell lung cancer. Thorax 2011;66:287-93.

35. Annema JT, van Meerbeeck JP, Rintoul RC, et al. Mediastinoscopy vs endosonography for mediastinal nodal staging of lung cancer: a randomized trial. JAMA 2010;304:2245-52.

36. Bousema JE, Dijkgraaf MGW, Papen-Botterhuis NE, et al. MEDIASTinal staging of non-small cell lung cancer by endobronchial and endoscopic ultrasonography with or without additional surgical mediastinoscopy (MEDIASTrial): study protocol of a multicenter randomised controlled trial. BMC Surg 2018;18:27.

37. Nakagawa K, Asamura H, Tsuta K, et al. The novel onestep nucleic acid amplification (OSNA) assay for the diagnosis of lymph node metastasis in patients with nonsmall cell lung cancer (NSCLC): Results of a multicenter prospective study. Lung Cancer 2016;97:1-7.

38. Inoue $M$, Hiyama K, Nakabayashi K, et al. An accurate and rapid detection of lymph node metastasis in non-small cell lung cancer patients based on one-step nucleic acid amplification assay. Lung Cancer 2012;78:212-8. 